\title{
Congenital Diaphragmatic Hernia Revealed by an Inaugural Diabetic Ketoacidosis in a 9-Year-Old Child
}

\author{
C. Mboutol-Mandavo1*, E. Moyen², P. Mawandza3, G. F. Otiobanda3 , A. Oko², I. P. L. Ondima1, \\ M. Elombila ${ }^{3}$, J.-C. Miéret ${ }^{1}$ \\ ${ }^{1}$ Department of Paediatric Surgery, University Hospital of Brazzaville, Brazzaville, Republic of the Congo \\ ${ }^{2}$ Department of Paediatric Reanimation, University Hospital of Brazzaville, Brazzaville, Republic of the Congo \\ ${ }^{3}$ Department of Anaesthesiology and Reanimation, University Hospital of Brazzaville, Brazzaville, Republic of the Congo \\ Email: *carymbout@gmail.com
}

How to cite this paper: Mboutol-Mandavo, C., Moyen, E., Mawandza, P., Otiobanda, G.F., Oko, A., Ondima, I.P.L., Elombila, M. and Miéret, J.-C. (2019) Congenital Diaphragmatic Hernia Revealed by an Inaugural Diabetic Ketoacidosis in a 9-Year-Old Child. Open Journal of Pediatrics, 9, 296-301.

https://doi.org/10.4236/ojped.2019.94028

Received: September 15, 2019

Accepted: November 17, 2019

Published: November 20, 2019

Copyright $\odot 2019$ by author(s) and Scientific Research Publishing Inc. This work is licensed under the Creative Commons Attribution International License (CC BY 4.0).

http://creativecommons.org/licenses/by/4.0/

\begin{abstract}
Introduction: Congenital diaphragmatic hernia is often detected during the prenatal or neonatal period by severe respiratory symptoms. Late-presenting congenital diaphragmatic hernia is uncommon entity resulting in frequent misdiagnosis and inappropriate treatment. Case Report: We report the case of a left congenital diaphragmatic hernia revealed by an inaugural diabetic ketoacidosis in a 9-year-old girl. She has presented progressive weight loss without loss of appetite associated with polyuro-polydipsia, then epigastric pain with vomiting. Blood glucose was $3.2 \mathrm{~g} / \mathrm{L}$, ketonuria and 2+ glycosuria. Despite a well-conducted treatment, there was persistence of dyspnea. Chest $\mathrm{X}$-ray and chest CT-scan confirmed the presence of a left diaphragmatic hernia. Evolution was marked by the death of the child on day 2 post-operative from a multivisceral failure. Conclusion: Clinical and radiological signs of congenital diaphragmatic hernia after the neonatal period may be difficult to interpret and may result in delayed diagnosis, erroneous treatment and potentially fatal outcome.
\end{abstract}

\section{Keywords}

Inaugural Diabetic Ketoacidosis, Late-Presenting Congenital Diaphragmatic Hernia, Child

\section{Introduction}

Congenital diaphragmatic hernia $(\mathrm{CDH})$ is a rare malformation observed in approximately 1 for 3000 live births [1]. In more than $90 \%$ of cases, $\mathrm{CDH}$ is de- 
tected during the prenatal or neonatal period. Infants with $\mathrm{CDH}$ often present at birth with severe respiratory symptoms. In these cases, there are few diagnostic problems. However, about $5 \%$ to $30 \%$ of diaphragmatic hernias are diagnosed beyond the neonatal period [2] [3] [4]. It poses diagnostic problems, because the late-presenting congenital diaphragmatic hernia is accompanied by a diagnostic wandering because of its rarity and its unusual semiology that can lead to inappropriate treatment and a fatal outcome. Indeed, it can be revealed in an acute or chronic mode by gastrointestinal or respiratory symptoms, or both. The massive pneumothorax and pleural effusion are the most common initial incorrect diagnosis at the chest radiography. Although the passage of a nasogastric tube placement or upper gastrointestinal opacification is an alternative method of confirming the diagnosis, computed tomography scan is recommended to confirm the diagnosis and avoid inappropriate chest drain placement when congenital diaphragmatic hernia is suspected in child and adult [5]. We report the case of a left congenital diaphragmatic hernia revealed by an inaugural diabetic ketoacidosis in a 9-year-old girl.

\section{Case Report}

B.O is a 9-year-old girl, with no notable pathological history. Since one month before her admission, she has presented progressive weight loss without loss of appetite associated with polyuro-polydipsia, then epigastric pain with vomiting. The installation of dyspnea with impaired consciousness justified her admission at the paediatric intensive care department. On examination, she was febrile, drowsy with Kussmaul dyspnea with dehydration and tachycardic. On abdominal examination, there was moderate bloating and generalized abdominal defense with dullness. Glycemia was $3.2 \mathrm{~g} / \mathrm{L}$, Ketonuria and glycosuria were at 2+. A treatment was instituted based on insulin and rehydration with isotonic saline serum. She needed high-flow oxygen to maintain oxygen saturation. The evolution was marked by the improvement of his state of consciousness, blood sugar $(0.75 \mathrm{~g} / \mathrm{L})$, ketonuria and glycosuria reduced to traces (Table 1$)$; but there was a persistence of respiratory symptoms and abdominal pain. Chest and abdominal radiographs were requested and showed the presence of gastric pouch and colon in the left hemithorax (Figure 1). These images were taken for pneumothorax and a thoracocentesis was performed without improvement of its clinical condition. A thoracoabdominal computed tomography was then performed confirming the diagnosis of left diaphragmatic hernia with gastro-pleural fistula (Figure 2). After clinical stabilization, she was operated on. We found a diaphragmatic defect about $10 \mathrm{~cm}$ wide (Figure 3), two large gastric perforations with presence of gastric fluid in the left hemithorax, perforation of the transverse colon and atrophic and infarcted spleen. We proceeded to diaphragmatic raphy repair by separate U-shaped stitches with nonabsorbable yarn (Figure 4), followed by closure of gastric and colonic breach and then splenectomy. She had also received antibiotic therapy with Ceftriaxone 2000 grams and Metronidazole $1200 \mathrm{~g}$ per 
day, combined with analgesics. Evolution was marked by the death of the child after 2 days postoperative by a multivisceral failure.

Table 1. Results of the laboratory investigations.

\begin{tabular}{cccc}
\hline Laboratory investigations & At admission & Day 1 & Day 2 \\
\hline Glycemia & $3.2 \mathrm{~g} / \mathrm{ml}$ & 1.25 & $0.75 \mathrm{~g} / \mathrm{ml}$ \\
Glucosuria & ++ & + & Traces \\
ketonuria & ++ & + & Traces \\
Blood creatinine & $9 \mathrm{mg} / \mathrm{L}$ & \\
Haemogram & & & \\
White blood cells & $13,500 / \mathrm{mm}^{3}$ & & \\
Red cells & $2.5 \times 10^{6} / \mathrm{mm}^{3}$ & & \\
Hemoglobin & $6.7 \mathrm{~g} / \mathrm{dL}$ & $10.1 \mathrm{~g} / \mathrm{dL}$ (after transfusion) & \\
\hline
\end{tabular}

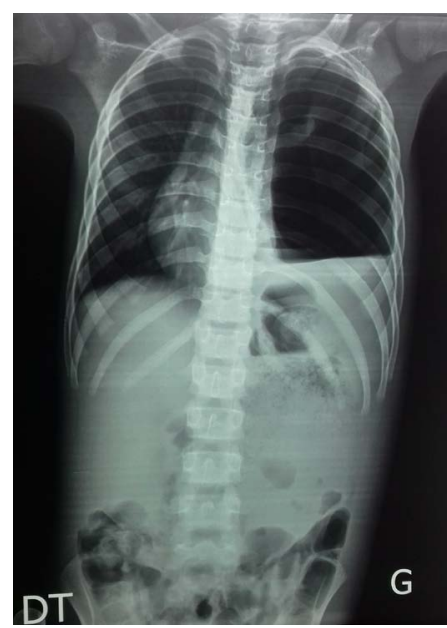

Figure 1. Standard thoracoabdominal radiograph showing left pneumothorax with intra-thoracic aerocoly.

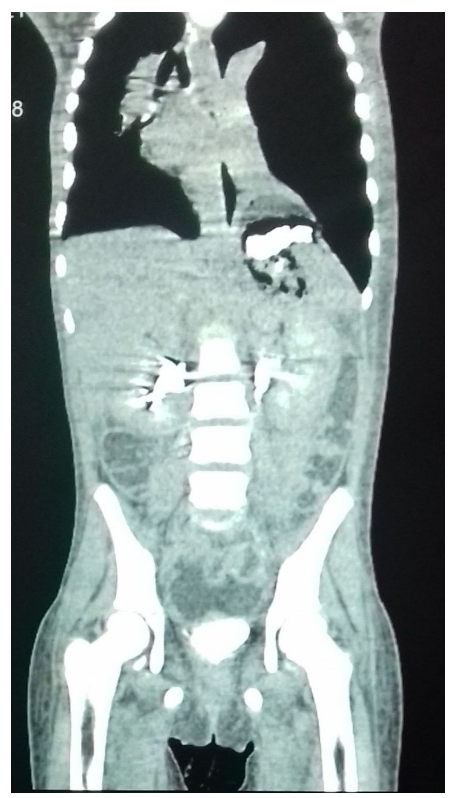

Figure 2. Thoracoabdominal CT scan showing left gastro-pleural fistula. 


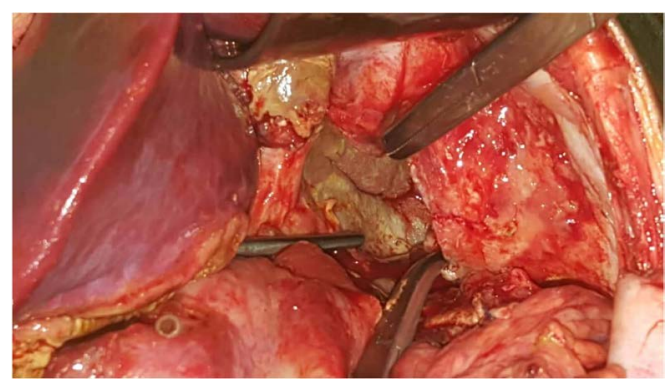

Figure 3. Diaphragmatic breach showing left lung.

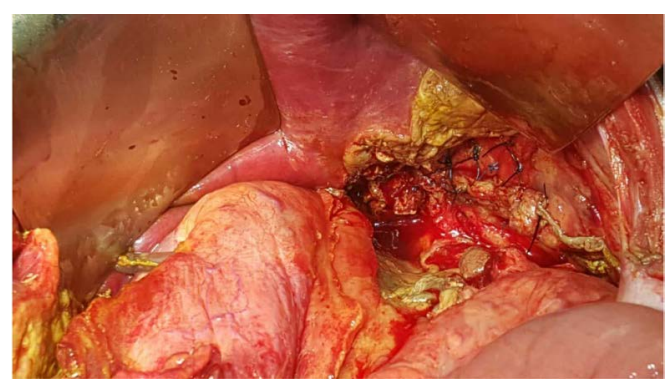

Figure 4. Aspect after closing of the diaphragmatic breach.

\section{Discussion}

Late-presenting $\mathrm{CDH}$ is a $\mathrm{CDH}$ diagnosed after the neonatal period [5]. It causes diagnostic difficulties because of its rarity and its varied clinical expression that can be respiratory or gastrointestinal, or both. Sometimes, it is fortuitous discovery; often it is the cause of a misdiagnosis [2] [3] [4]. Indeed most cases reported in the literature, late-presenting HDC manifests by respiratory symptoms misdiagnosed as pneumonia, congenital pulmonary cysts or pneumothorax [6] [7], or by gastrointestinal disorders non-specific such as vomiting, acute, chronic or recurrent abdominal pain depending of the importance of viscera contained in the sac [8] [9]. Sridhar et al. [10] explained that in such cases, the defect is long standing but the viscera are confined by the hernial sac or obturated by a solid organ; the patient becomes symptomatic when actual herniation takes place later in life because of rupture of the hernial sac or complication of herniated contents, such as volvulus or strangulation.

In addition, the same symptoms can be found in diabetic ketoacidosis [11] [12]. One month before admission, the patient presented both respiratory and digestive symptoms evolving insidiously before presenting disorders of consciousness and Kussmaul respiration, related to an inaugural diabetic ketoacidosis. Treated as such, despite the glycaemic balance and the disappearance of ketones and sugar in the urine, respiratory symptoms (polypnea) persisted. A chest $\mathrm{X}$-ray revealed the diagnosis of a $\mathrm{CDH}$. We don't find in the literature cases of diaphragmatic hernia revealed by inaugural diabetic ketoacidosis, which makes this case exceptional. On standard radiography, the left intrathoracic air image is mistaken for a pneumothorax. This diagnostic wandering already reported by other authors [6] [8] [9], reason why we performed a thoracocentesis in our pa- 
tient. Berman et al. [6], in their series of 26 patients with late presenting $\mathrm{CDH}$ reported that 4 undergone thoracocentesis. Zaleska-Dorobisz et al. [13] in their series reported that 9 out of 29 patients undergone thoracocentesis. Standard radiography may be supplemented with esophago-gastric opacification or a barium enema; computed tomography or MRI is recommended only in case of diagnostic doubt [3] [6] [9]. In our case computed tomography of the chest revealed the diagnosis. It was a Bochdalek diaphragmatic hernia that is the most common type of $\mathrm{CDH}$ with $90 \%$ of cases [9].

A surgical treatment was performed as soon as her clinical status stabilized (on the third day of her admission to paediatric intensive care). During the operation, we found multiple gastric and colic perforations due to thoracic drainage in relation to previous diagnostic wandering. This has also been reported by other authors [9] [14]. The atrophy and infarction of the spleen indicate chronic suffering of this organ observed in the left $\mathrm{CDH}$ and may be the cause of haemorrhage with a vital risk [10]. It is possible that the spleen could have closed the diaphragmatic gap, and that its atrophy was responsible of hernia. This hypothesis has already been underlined by other authors [10]. And we also believe that there was preexisting gastric perforation to the pleural drainage because the CT scan had shown a gastro-pleural fistula.

The evolution was fatal in our case; Berman et al. [6] reported 2 deaths from cardiopulmonary arrest in apparently healthy children. The association of an inaugural diabetic ketoacidosis and a late-presenting diaphragmatic hernia is particularly morbid and fatal because of the severity of the two pathologies, with a potentiating effect of one on the other. On one hand, diabetic ketoacidosis is the leading cause of morbidity and mortality in children with type 1 diabetes mellitus; mortality is mainly related to the occurrence of cerebral oedema [11]. On the other hand, the late-diagnosis of diaphragmatic hernia was made at the stage of complications including gastric and colic perforation with diffusion of their contents in the abdominal and thoracic cavities. Indeed, all authors agree that late-diagnosis of $\mathrm{CDH}$ and erroneous treatment can lead to potentially significant morbidity and mortality when patients are not properly managed at an appropriate stage [6] [10] [14]. In our case, the child is brought to the hospital in a context of deterioration of the general condition with multi-organ failure.

\section{Conclusion}

The clinical signs and radiological findings of patients with congenital diaphragmatic hernia after the neonatal period may be difficult to interpret and may result in delayed diagnosis, erroneous treatment and potentially fatal outcome. It was the case in our patient who, in addition, had a second pathology, diabetes mellitus, revealed in its most lethal form, ketoacidosis.

\section{Conflicts of Interest}

The authors declare no conflicts of interest regarding the publication of this paper. 


\section{References}

[1] Ijsselstijn, H. and Tibboel, D. (1998) The Lungs in Congenital Diaphragmatic Hernia: Do We Understand? Pediatric Pulmonology, 26, 204-218.

https://doi.org/10.1002/(SICI)1099-0496(199809)26:3<204::AID-PPUL8>3.0.CO;2$\underline{\mathrm{K}}$

[2] Fotter, R., Schimpl, G., Sorantin, E., Fritz, K. and Landler, U. (1992) Delayed Presentation of Congenital Diaphragmatic Hernia. Pediatric Radiology Journal, 22, 187-191. https://doi.org/10.1007/BF02012491

[3] Brouard, J., Leroux, P., Jokic, M., Maguer, D., Chevet, J.-B. and Ravasse, P. (2000) Late-Presenting Congenital Diaphragmatic Hernia: Diagnosis Difficulties. Archives de Pédiatrie, 7, 48-51. https://doi.org/10.1016/S0929-693X(00)88819-3

[4] Zachariasse, J.J.M., Van Heurn, L.W.E., Dompeling, E. and Been, J.V. (2011) Late-Presenting Congenital Diaphragmatic Hernia. Archives of Disease in Childhood, 96, 697. https://doi.org/10.1136/archdischild-2011-300174

[5] Bagłaj, M. and Dorobisz, U. (2005) Late-Presenting Congenital Diaphragmatic Hernia in Children: A Literature Review. Pediatric Radiology, 35, 478-488. https://doi.org/10.1007/s00247-004-1389-Z

[6] Chang, S.W., Lee, H., Yeung, C.Y., Chan, T., Hsu, C.H., Kao, H.A., Hung, H.Y., Chang, J.H., Sheu, J.C. and Wang, N.L. (2010) A Twenty-Year Review of Early and Late-Presenting Congenital Bochdalek Diaphragmatic Hernia: Are They Different Clinical Spectra? Pediatrics and Neonatology, 51, 26-30. https://doi.org/10.1016/S1875-9572(10)60006-X

[7] Berman, L., Stringer, D., Ein, S.H. and Shandling, B. (1988) The Late-Presenting Pediatric Bochdalek Hernia: A 20-Year Review. Journal of Pediatric Surgery, 23, 735-739. https://doi.org/10.1016/S0022-3468(88)80414-7

[8] Ozturk, H., Karnak, I., Sakarya, M.T. and Cetinkursun, S. (2001) Late Presentation of Bochdalek Hernia: Clinical and Radiological Aspects. Pediatric Pulmonology, 31, 306-310. https://doi.org/10.1002/ppul.1045

[9] Hamid, R., Baba, A.A., Shera, A.H., Wani, S.A., Altaf, T. and Kant, H.M. (2014) Late-Presenting Congenital Diaphragmatic Hernia. African Journal of Paediatric Surgery, 11, 119-123. https://doi.org/10.4103/0189-6725.132799

[10] Sridhar, S.N. (2004) Late-Presenting Congenital Diaphragmatic Hernia. Emergency Medicine Journal, 21, 261-262. https://doi.org/10.1136/emj.2003.007435

[11] Dunger, D.B., Sperling, M.A., Acerini, C.L., Bohn, D.J., Daneman, D., Danne, T.P.A., et al. (2004) European Society for Paediatric Endocrinology/Lawson Wilkins Pediatric Endocrine Society Consensus Statement on Diabetic Ketoacidosis in Children and Adolescents. Pediatrics, 113, 133-140.

https://doi.org/10.1542/peds.113.2.e133

[12] Wolfsdorf, J., Glaser, N. and Sperling, M.A. (2006) Diabetic Ketoacidosis in Infant, Children and Adolescent. A Consensus Statement from the American Diabetes Association. Diabetes Care, 29, 1150-1159. https://doi.org/10.2337/dc06-9909

[13] Zaleska-Dorobisz, U., Bagłaj, M., Sokołowska, D., Ładogórska, J. and Moroń, K. (2007) Late Presenting Diaphragmatic Hernia: Clinical and Diagnostic Aspects. Medical Science Monitor, 13, 137-146.

[14] Mei-Zahav, M., Solomon, M., Trachsel, D. and Langer, J.C. (2003) Bochdalek Diaphragmatic Hernia: Not Only a Neonatal Disease. Archives of Disease in Childhood, 88, 532-535. https://doi.org/10.1136/adc.88.6.532 